\title{
WOMEN VS MEN - TECHNICAL AND TACTICAL EFFICIENCY IN FOOTBALL
}

\author{
Tudor PALADE ${ }^{1 *}$, Gheorghe GRIGORE ${ }^{1}$, Garry BARREL $^{2}$ \\ ${ }^{1}$ National University of Physical Education and Sport, Faculty of Physical Education and Sport, Bucharest, \\ Romania \\ ${ }^{2}$ This Girls Kicks Club, London, UK \\ *Corresponding author: paladetudor@yahoo.com
}

https://doi.org/10.35189/dpeskj.2020.59.3.7

\begin{abstract}
Women's football is the sports game with the most spectacular development in recent years both in terms of the number of participants (approximately 40 million) and all other factors involved in this process (international federations, investments, spectators, etc.). The general perception that most specialists have about women's football is: "Like amateur football, but in slow motion". This perception has fundamentally changed with the significant improvement in the level of performance shown on the field by football players. The questions we are trying to answer by conducting this research are the following: Are there important technical and tactical differences between women's and men's high-performance football? If there are such differences, what relevance do they have for the preparation process? In this context, the present study represents a comparative analysis, from a technical and tactical point of view, of the teams ranked in the top 3 at the last World Cups for both men (2018 FIFA World Cup Russia) and women (2019 FIFA Women's World Cup France). The data were obtained from the FIFA website and from live statistics provided during each World Cup game. The conclusions that will emerge from this study may represent directions for the further technical and tactical development of women's football.
\end{abstract}

Keywords: efficiency, men's football, technical and tactical analysis, women's football.

\section{Introduction}

The development of women's football has now reached a level that few people could have imagined. The media in general and television in particular are increasingly permeable to host matches and broadcast competitions in which women's football is present (Meier et al., 2016). The question we want to answer is: "Will women one day be better at football than men?" We do not have the answer to this question but, with the help of this research, we try to identify the technical and tactical level of expression of the most valuable national football teams (both men and women).

No one can deny that women's football has had a winding path from its beginnings to the present day, with discrimination and oppression as defining characteristics. But objectively and scientifically, could the level of football shown by women be higher than that of men?

One of the main physiological differences between male and female athletes in general is the large difference in "hormonal factors" (women have lower testosterone levels than men but much higher oestrogen). These differences become evident in the specific responses or magnitude of the response to various training regimens (Lewis et al. 1986). "If we want to increase performance in women's football, we will have to focus on the study of its conditional, technical, tactical-strategic, volitional and socio-affective structure" (Casal et al., 2020, p. 2). 
The growing popularity of women's football worldwide has led to an increase in the number of scientific research papers investigating the characteristics and requirements of the game, although they are not yet as numerous as in the case of men's football (MartinezLagunas et al., 2014; Sainz de Baranda et al., 2019). The literature tracks especially the differences of physical (somatic, functional, motor) nature between genders and less the technical and tactical ones specific to the game. A study aimed at these components of training was conducted by Hjelm (2001), who made a comparative analysis of technical errors (passes, receptions, dribbling, shots, actions with a negative outcome) between male and female players of the Swedish national team. Results showed that technical differences were found between genders; specifically, male football players performed more short passes and receptions, and female football players performed more actions with a negative outcome, more dribbling and more shots on target (Casal et al., 2020).

In an analysis on the technical and tactical level shown by the national teams at the World Championships (2002 FIFA World Cup vs 2003 FIFA Women's World Cup), Althoff et al. (2010) conclude that women use more long passes than short ones and instep kicks, perform less dribbling, have a less aggressive game (less tackling) and try to get closer to the goal before shooting due to their lack of strength.

Trying to compare the results of our study with those of other research, we have found that there are a number of studies focused on the analysis of matches in women's football. Soroka and Bergier (2010) investigated the characteristics of attack and defence actions to win or lose in women's football. Hewitt et al. (2014) reported a different game activity between higher and lower ranked teams in women's football.

Comparative analysis over time of the performance models of winning teams in major international competitions highlights how playing styles evolve and identifies those variables (such as ball possession and free kicks for attack or defensive organization and defensive pressing) that are considered the most important in today's football (Castellano et al., 2012; Sarmento et al., 2014).

Technical and tactical action is the cumulative effect of nerve connections conditioning the coordination of movements and the simultaneous engagement, but in different proportions, of conditional abilities. Motor coordination is determined by the stages of learning the techniques established by methodology, which results from the interdependence between pedagogical and psychological information (D'Ottavio, 1998). The technical, tactical and physical attributes of male and female footballers differ (Kirkendall et al., 2002) when comparing the strategies of both genders used at the 1998 and 1999 FIFA World Cup Tournaments in France and Brazil, respectively.

Even if today's football is characterised by the requirement for the player to move more and faster, the game is more than just a physical contest but a test of technical and psychological skills. Bradley and Noakes (2013) suggested that the total time in possession of the ball and the total number of touches and duels won were the same for male and female players; however, they said that male footballers had better pass completion and lost possession less often than females at a similar standard of competition.

As a major competition, the World Cup represents the main model that inspires top performance teams from a physical, technical, tactical, psychological and theoretical point of view. A current requirement of the football game refers to the quick transition from defence 
to attack and vice versa, as a consequence of taking possession of the ball/ losing the ball by surprising the opposing team.

\section{Problem statement}

The tasks of this scientific approach were to highlight:

- The current level of knowledge on the topic addressed;

- Technical and tactical similarities and differences between men's and women's football;

- A comparison between the level shown by men's and women's national teams at the last two World Cups.

\section{Research questions}

As regards the technical and tactical efficiency in men's vs women's football, the following questions arise:

- Are there important differences between men's and women's teams in terms of value of the most important technical and tactical indicators?

- What are the technical and tactical development directions that women's football must follow in order to reduce the difference compared to men's football?

\section{Purpose of study}

The research aims to detect the technical and tactical differences that exist in today's football between men and women and highlight the direction in which the latter can progress.

\section{Methodology}

To carry out the research, we used the following methods: video analysis, observation, mathematical and statistical processing, and graphical method.

\section{Content of research}

This study represents a technical and tactical comparative analysis of the teams ranked in the top 3 at the last World Cups for both men (2018 FIFA World Cup Russia) and women (2019 FIFA Women's World Cup France). The data were obtained from the FIFA technical reports (FIFA, 2018; FIFA, 2019) and from live statistics provided during each World Cup game ("Live Scores Summary", n.d.). The recorded statistical indicators, highlighted with the help of the tables and graphs below, were divided into three categories:

- standard statistics (Goals scored, Goals inside penalty area, Goals outside penalty area, Open-play goals, Set-piece goals, Own-goals, Goals conceded, Goals conceded inside penalty area, Goals conceded outside penalty area, Open-play goals conceded, 
Set-piece goals conceded, Own-goals conceded, Assists, Penalty kicks made, Penalty kicks attended, Yellow cards, Red cards);

- passing \& possession, shooting and goalkeeper statistics (Total shots, Shots on target, Shots from free kick, Goals per shot, Goals per shot on target, Passes completed, Pass completion percentage, Average possession/match, Dribbles attended, Dribbles completed successfully, Number of players dribbled past, Goalkeeper completed passes/match, Goalkeeper completed pass percentage);

- defensive action statistics (Number of players tackled, Tackles won, Pressures, Successful pressures, Successful pressure percentage, Blocks, Interceptions, Clearances).

\section{Results and Discussion}

Before presenting the recorded statistical indicators, we will perform a technical and tactical general comparative analysis of the two World Cups: 2018 World Cup Russia (MWC) vs 2019 Women's World Cup France (WWC). In making this comparison, we took into account the video analysis performed by us as well as the FIFA technical reports.

Goal analysis:

- At the 2018 MWC, many goals were scored, namely 169 (an average of 2.64 goals/ match), only two less than the record for a 32-team World Cup, which was set in France, in 1998, and evened in Brazil, in 2014. According to specialists, this large number of goals is due to the lack of pressure on the man with the ball. This indicates that the teams focused more on the offensive phase and were very good at taking their chances; shooting efficiency from outside the penalty area improved sharply compared to Brazil 2014 (the average shooting rate was 1 goal per 29 long-range attempts in 2018 MWC compared to 1 goal per 42 in 2014 MWC). Another important feature of this Final Tournament is related to the use of either counter-attacks or set pieces ( 1 in every 2 goals was scored during these forms of attack).

- At the 2019 WWC, 146 goals were scored (an average of 2.8 goals/match), but if we do not take into account the goals scored by the US team in their first match (vs Thailand, 13-0), we get an average very close to that of men, 2.6 goals/match. Unlike men's games, in 2019 WWC, $87 \%$ of the games were won by the team that hit first, with an increase from 71\% in 2015 and 67\% in 2011. This World Cup also highlighted the players' ability to use wide areas and transmit long and precise passes, thus creating many openings in front of goal for "displays of pure aerial goal-scoring prowess" (Lewis, 2019).

Set pieces:

- In today's football, which is characterised by an obvious value balance between the teams participating in a competition, the fixed phases can be the decisive moments of a game. The best example of the importance of set pieces in this tournament is offered by the champion team itself, notably in the semi-final against Belgium and then again in the final against Croatia. Apart from penalties, the major change in this tournament in terms of decisive moments was related to corners. At the 2018 World Cup, 1 in 
every 29 corners led to a goal, compared to Brazil 2014 with 1 in 36 . This trend of superior effectiveness continued throughout the knockout stage in MWC Russia, where the teams scored from the corner once in every 31 such moments compared to every 41 in Brazil.

- The same trend is noted at the 2019 WWC, where $27 \%$ of the total goals scored (40) were achieved in fixed phases. The improvement of players' aerial game increased the above-mentioned percentage and made the number of goals scored with the head higher than in previous World Cups. In France, there were 10 matches decided by kicks stemming from set pieces. An average of 36 corners were needed to score in WWC France and, although not quite as efficient as the 28 required at the $2015 \mathrm{WWC}$ Canada, this still attests to a high degree of effectiveness compared to men.

Offensive organization:

- The importance of the playmaker was not as pronounced as in other World Cups but the teams that reached the final stages of the competition had players with special technical and tactical skills (Luca Modric, Paul Pogba, Eden Hazard etc).

- In the case of women, we observed that there was a concern for the coaches to build from behind the defenders, with central defenders confidently waiting to find an opening to play a penetrating pass through to the midfielders, who managed to position themselves between the defensive lines. The teams also displayed confidence in their ability to maintain possession when building, positioning themselves with defenders in the neutral zone, as fullbacks were permitted to progress into more advanced positions, giving central defenders an extra option up the wing when funnelling play through the middle of the pitch was proving difficult. Another tactical element characteristic of this Final Tournament consisted in the positional fluidity (permanent movement of players during the attack phase).

Defensive organization:

- All teams participating in the 2018 MWC were more compact in defence, with a tournament average of $26 \mathrm{~m}$ the distance between the first and the last defender. The decrease in the number of shots on goal from outside the penalty area (at this World Cup, there were $32 \%$ fewer such actions than in South Africa) is explained by the use of strict and compact defences. Defending in this style requires efficient organization, good teamwork, awareness, and communication between players.

- "Very careful defensive organization" was also one of the main objectives for women. However, the finalists preferred to press the opponent immediately after losing possession of the ball rather than retreat to their own half of the field. In support of this statement are the statistics showing that the French team had an average ballrecovery height (the average distance from their own goal when regaining possession) of just under $50 \mathrm{~m}$, followed by the US team, with $48 \mathrm{~m}$.

Goalkeeping analysis:

- Goalkeepers played a decisive role in many matches of this World Cup (2018 MWC), especially in the knockout stages where several games were decided after the penalty kicks. In the previous section on defensive organization, it was noted "how compactly and deeply teams defended at this World Cup. As a result, goalkeepers' vision will 
have been reduced and they will have had less time to react" due to "the risk of wicked deflections, and a number of goals were conceded in this manner" (FIFA, 2018, p. 12).

- "The space behind the defensive line was a key battleground in France and one that the goalkeepers played an important role in guarding" (FIFA, 2019, p. 11). Thus, the qualities shown by most goalkeepers in this tournament were: game-reading ability, situational awareness, ability to attack the ball by intercepting it as early as possible and clearing many dangerous situations before they could develop. Another area where goalkeepers stamped their authority on the game was their consistent endeavour to claim crosses.

Table 1. General statistical parameters

\begin{tabular}{|c|c|c|c|c|c|c|c|c|}
\hline \multirow{2}{*}{\multicolumn{2}{|c|}{ Statistical parameters }} & \multirow[t]{2}{*}{ Abbreviation } & \multicolumn{3}{|c|}{ Women } & \multicolumn{3}{|c|}{ Men } \\
\hline & & & USA & Netherlands & Sweden & France & Croatia & Belgium \\
\hline \multirow{17}{*}{ 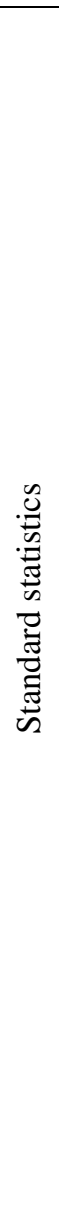 } & Goals scored & Gls & 26 & 11 & 12 & 14 & 14 & 16 \\
\hline & $\begin{array}{l}\text { Goals inside } \\
\text { penalty area }\end{array}$ & GlsIPA & 18 & 10 & 11 & 10 & 13 & 15 \\
\hline & $\begin{array}{l}\text { Goals outside } \\
\text { penalty area }\end{array}$ & GlsOPA & 8 & 1 & 1 & 4 & 1 & 1 \\
\hline & $\begin{array}{l}\text { Open-play } \\
\text { goals }\end{array}$ & OPGls & 16 & 5 & 10 & 9 & 12 & 15 \\
\hline & Set-piece goals & SPGls & 9 & 6 & 2 & 5 & 2 & 1 \\
\hline & Own-goals & Ogls & 1 & 0 & 0 & 0 & 0 & 0 \\
\hline & Goals conceded & GlsCon & 3 & 5 & 6 & 6 & 9 & 6 \\
\hline & $\begin{array}{l}\text { Goals conceded } \\
\text { inside penalty } \\
\text { area }\end{array}$ & GlsConIPA & 2 & 5 & 5 & 5 & 5 & 5 \\
\hline & $\begin{array}{l}\text { Goals conceded } \\
\text { outside penalty } \\
\text { area }\end{array}$ & GlsConOPA & 1 & 0 & 1 & 1 & 4 & 1 \\
\hline & $\begin{array}{l}\text { Open-play } \\
\text { goals conceded }\end{array}$ & OPGlsCon & 2 & 4 & 4 & 5 & 3 & 4 \\
\hline & $\begin{array}{l}\text { Set-piece goals } \\
\text { conceded }\end{array}$ & SPGlsCon & 1 & 1 & 1 & 1 & 6 & 2 \\
\hline & $\begin{array}{l}\text { Own-goals } \\
\text { conceded }\end{array}$ & OGlsCon & 0 & 0 & 1 & 0 & 0 & 0 \\
\hline & Assists & Ast & 17 & 7 & 7 & 6 & 8 & 12 \\
\hline & $\begin{array}{l}\text { Penalty kicks } \\
\text { made }\end{array}$ & PK & 3 & 1 & 1 & 3 & 8 & 1 \\
\hline & $\begin{array}{l}\text { Penalty kicks } \\
\text { attended }\end{array}$ & PKatt & 4 & 1 & 1 & 3 & 12 & 1 \\
\hline & Yellow cards & $\mathrm{CrdY}$ & 7 & 6 & 7 & 12 & 15 & 11 \\
\hline & Red cards & CrdR & 0 & 0 & 0 & 0 & 0 & 0 \\
\hline
\end{tabular}




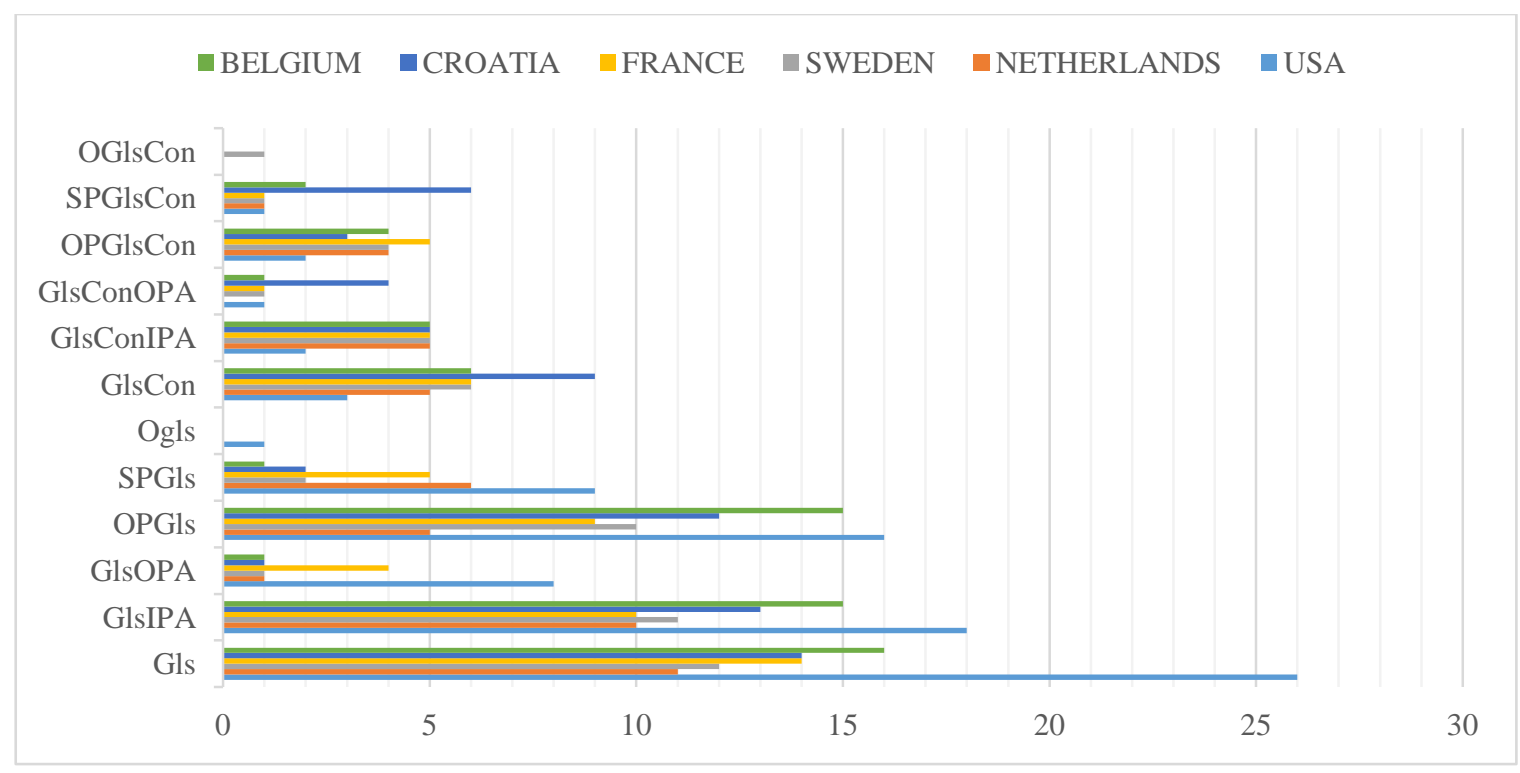

Figure 1. Goals scored/conceded

The results recorded in Table 1 help us highlight the following aspects:

- The analysis related to the number of goals scored by the studied teams is difficult to achieve due to the incredible result of the US women's team in the first match (13-0 vs Thailand). With the exception of this remarkable result, we observe close values of the number of goals, so we can say that the offensive concern has common features;

- Regarding the finishing area, we note the concern of the USA for women and Belgium for men to finish from the penalty area, while the long-distance finish is the characteristic feature of the winning teams of the World Cups. It is possible that this characteristic of the game played by the two teams made the difference for winning the competition;

- The situation of set-piece goals shows an imbalance between genders: women's teams scored more than double the number of goals (17) compared to men's teams (8);

- The defensive tactical strategy chosen by women's teams (advanced defence and ball recovery away from their own goal) led to increased effectiveness compared to male players (14 vs 21);

- We also notice the vulnerability of the Croatian team at the fixed moments of the game, given that it received a very large number of goals (6). However, we must keep in mind that this team played the most minutes in the Final Tournament ( 3 matches were decided after the penalty kicks);

- Regarding the number of cards received, we notice that men's football is much tougher than women's, the number of yellow cards received by men being almost double compared to women ( 38 vs 20). However, the teams ranked in the top 3 at these two World Cups were not put in the difficult situation of playing with one man in minus (none received a red card). 
Table 2. Passing, possession and shooting statistics

\begin{tabular}{|c|c|c|c|c|c|c|c|c|}
\hline \multicolumn{2}{|r|}{ Statistical parameters } & \multirow[t]{2}{*}{ Abbreviation } & \multicolumn{3}{|c|}{ Women } & \multicolumn{3}{|c|}{ Men } \\
\hline \multirow{6}{*}{ 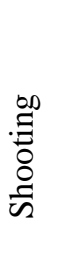 } & & & USA & Netherlands & Sweden & France & Croatia & Belgium \\
\hline & Total shots & Sh & 126 & 85 & 104 & 79 & 112 & 107 \\
\hline & Shots on target & SoT & 51 & 27 & 38 & 26 & 27 & 35 \\
\hline & Shots from free kick & FK & 1 & 4 & 1 & 6 & 5 & 4 \\
\hline & Goals per shot & $\mathrm{G} / \mathrm{Sh}$ & 0.17 & 0.12 & 0.11 & 0.11 & 0.04 & 0.13 \\
\hline & $\begin{array}{l}\text { Goals per shot on } \\
\text { target }\end{array}$ & G/SoT & 0.43 & 0.37 & 0.29 & 0.35 & 0.19 & 0.4 \\
\hline \multirow{6}{*}{ 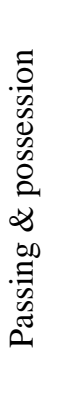 } & Passes completed & $\mathrm{Cmp}$ & 2724 & 2987 & 2382 & 2600 & 3178 & 3202 \\
\hline & $\begin{array}{l}\text { Pass completion } \\
\text { percentage }\end{array}$ & Cmp\% & $74.40 \%$ & $77.40 \%$ & $74 \%$ & $79.80 \%$ & $78.20 \%$ & $84.70 \%$ \\
\hline & $\begin{array}{l}\text { Average possession/ } \\
\text { match }\end{array}$ & AvgPoss $\%$ & $55 \%$ & $56 \%$ & $48 \%$ & $48 \%$ & $56 \%$ & $53 \%$ \\
\hline & Dribbles attended & DrbAtt & 187 & 133 & 120 & 138 & 109 & 114 \\
\hline & $\begin{array}{l}\text { Dribbles completed } \\
\text { successfully }\end{array}$ & DrbSucc & 106 & 75 & 72 & 79 & 78 & 77 \\
\hline & $\begin{array}{l}\text { Number of players } \\
\text { dribbled past }\end{array}$ & $\# \mathrm{Pl}$ & 114 & 83 & 73 & 88 & 83 & 88 \\
\hline
\end{tabular}

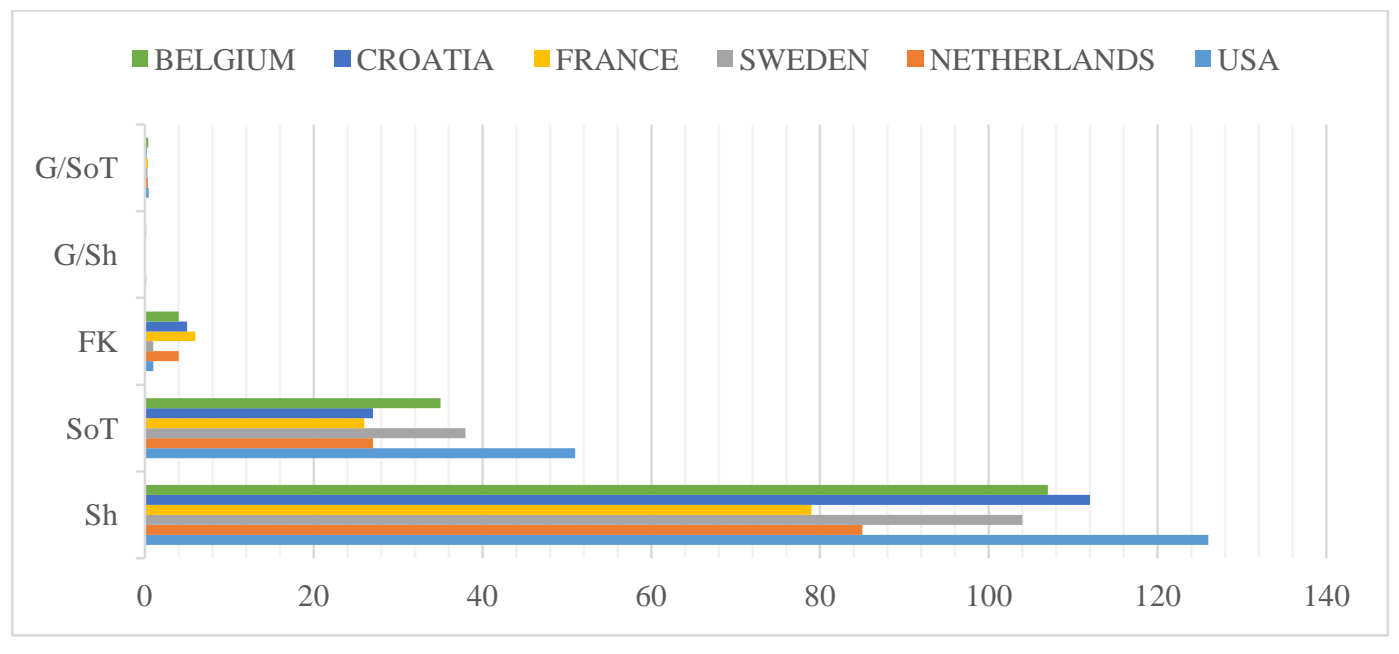

Figure 2. Shooting statistics

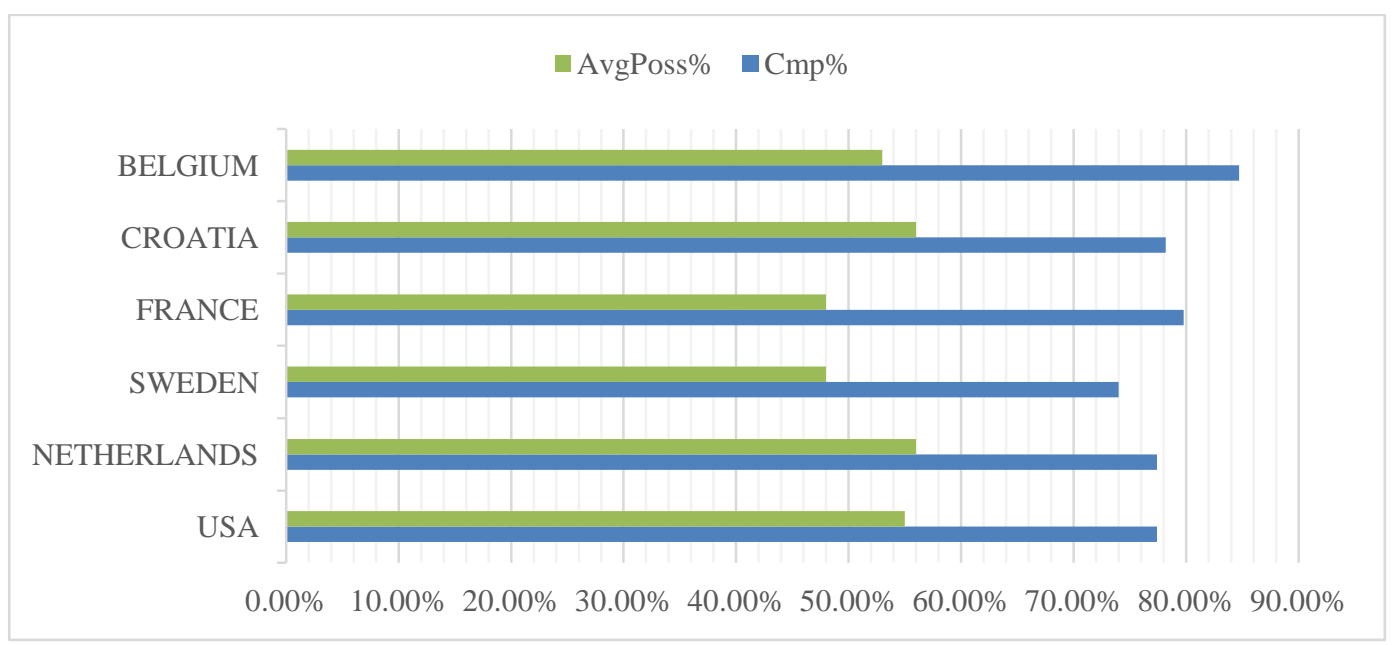

Figure 3. Passing \& possession statistics 
Table 2 shows the statistical indicators related to building the attacking game (passing \& possession) and ways to complete it (shooting). Analysing them, we notice the following:

- The average number of shots on goal per game is substantially equal between men and women (14.2 vs 15), which is a fairly high value;

- In the case of shots on goal, the gender difference is important in favour of women (28 more shots);

- Regarding the percentage of successful passes, there is a balance between the studied teams $(+70 \%)$, with the exception of Belgium that exceeded the percentage of $80 \%$;

- Analysing the average possession per match, we can say that it is no longer relevant for victory either in men or women. Our statement is based on the fact that, in a ranking of possession per match, none of the studied teams is in the top 5, and the difference from the first ranked is quite large;

- Regarding the ratio between attended and successful dribbles, we notice a higher percentage for men $(8.4 \%)$ compared to women; in other words, men are more effective than women in 1 vs 1 duels.

Table 3. Defensive actions \& goalkeeper statistics

\begin{tabular}{|c|c|c|c|c|c|c|c|c|}
\hline \multirow{2}{*}{\multicolumn{2}{|c|}{ Statistical parameters }} & \multirow[t]{2}{*}{ Abbreviation } & \multicolumn{3}{|c|}{ Women } & \multicolumn{3}{|c|}{ Men } \\
\hline & & & USA & Netherlands & Sweden & France & Croatia & Belgium \\
\hline \multirow{7}{*}{ 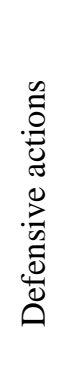 } & $\begin{array}{l}\text { Number of players } \\
\text { tackled }\end{array}$ & Tkl & 136 & 204 & 130 & 107 & 91 & 89 \\
\hline & Tackles won & TklW & 87 & 122 & 85 & 64 & 57 & 62 \\
\hline & Pressures & Press & 873 & 1180 & 1151 & 1314 & 1151 & 1432 \\
\hline & Successful pressures & Succ & 321 & 388 & 329 & 346 & 320 & 270 \\
\hline & $\begin{array}{l}\text { Successful pressure } \\
\text { percentage }\end{array}$ & $\%$ & 36.8 & 32.9 & 28.6 & 26.3 & 27.8 & 18.9 \\
\hline & Blocks & Blocks & 92 & 133 & 127 & 90 & 100 & 79 \\
\hline & Interceptions & Int & 76 & 100 & 70 & 74 & 72 & 56 \\
\hline & Clearances & $\mathrm{Clr}$ & 183 & 174 & 167 & 122 & 155 & 113 \\
\hline 这 & $\begin{array}{l}\text { Goalkeeper } \\
\text { completed passes/ } \\
\text { match }\end{array}$ & GkCmp & 21 & 24 & 31 & 26 & 32 & 33 \\
\hline 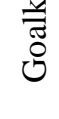 & $\begin{array}{l}\text { Goalkeeper } \\
\text { completed pass } \\
\text { percentage }\end{array}$ & $\mathrm{GkCmp} \%$ & $71 \%$ & $79 \%$ & $72 \%$ & $68 \%$ & $73 \%$ & $80 \%$ \\
\hline
\end{tabular}




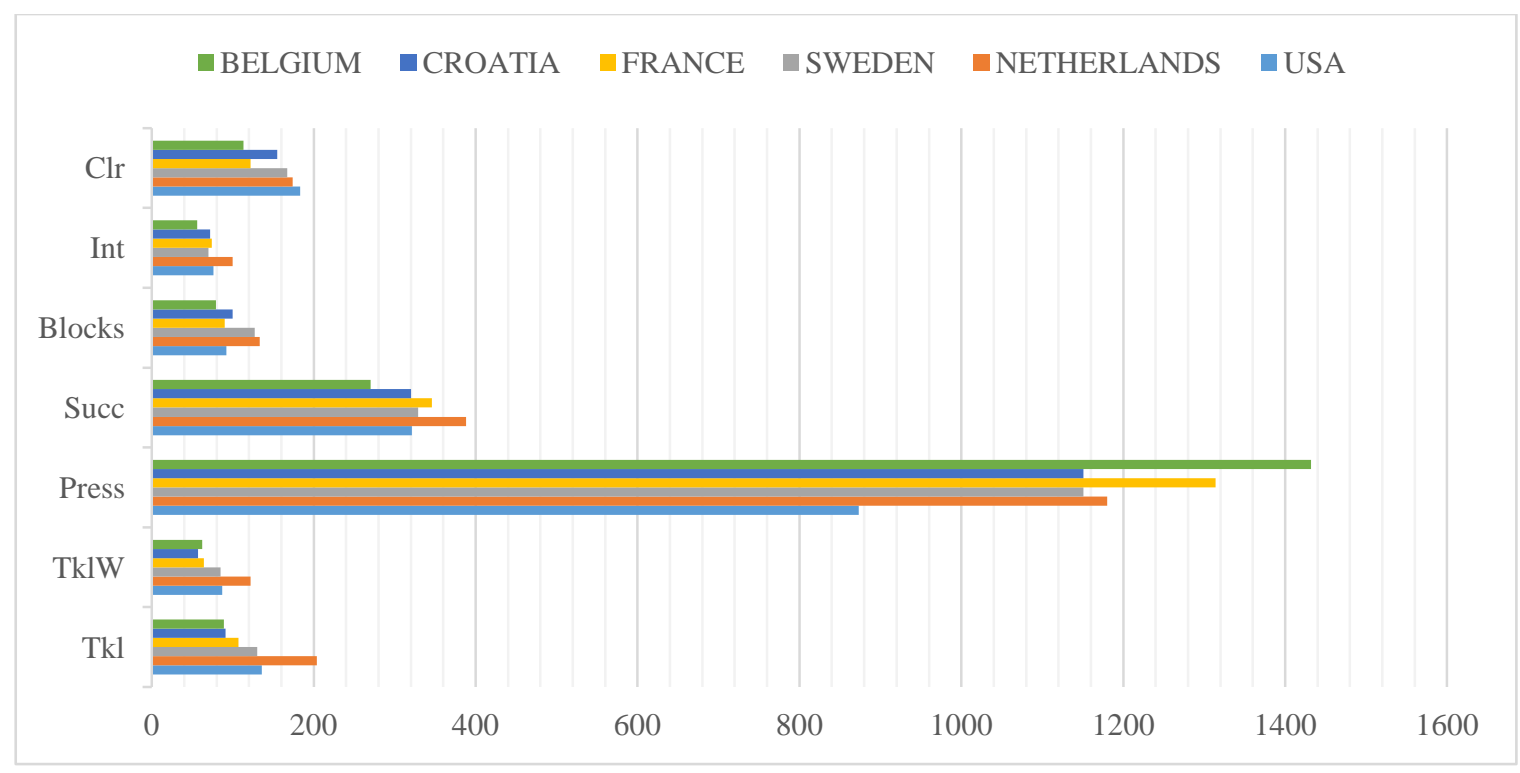

Figure 4. Defensive action statistics

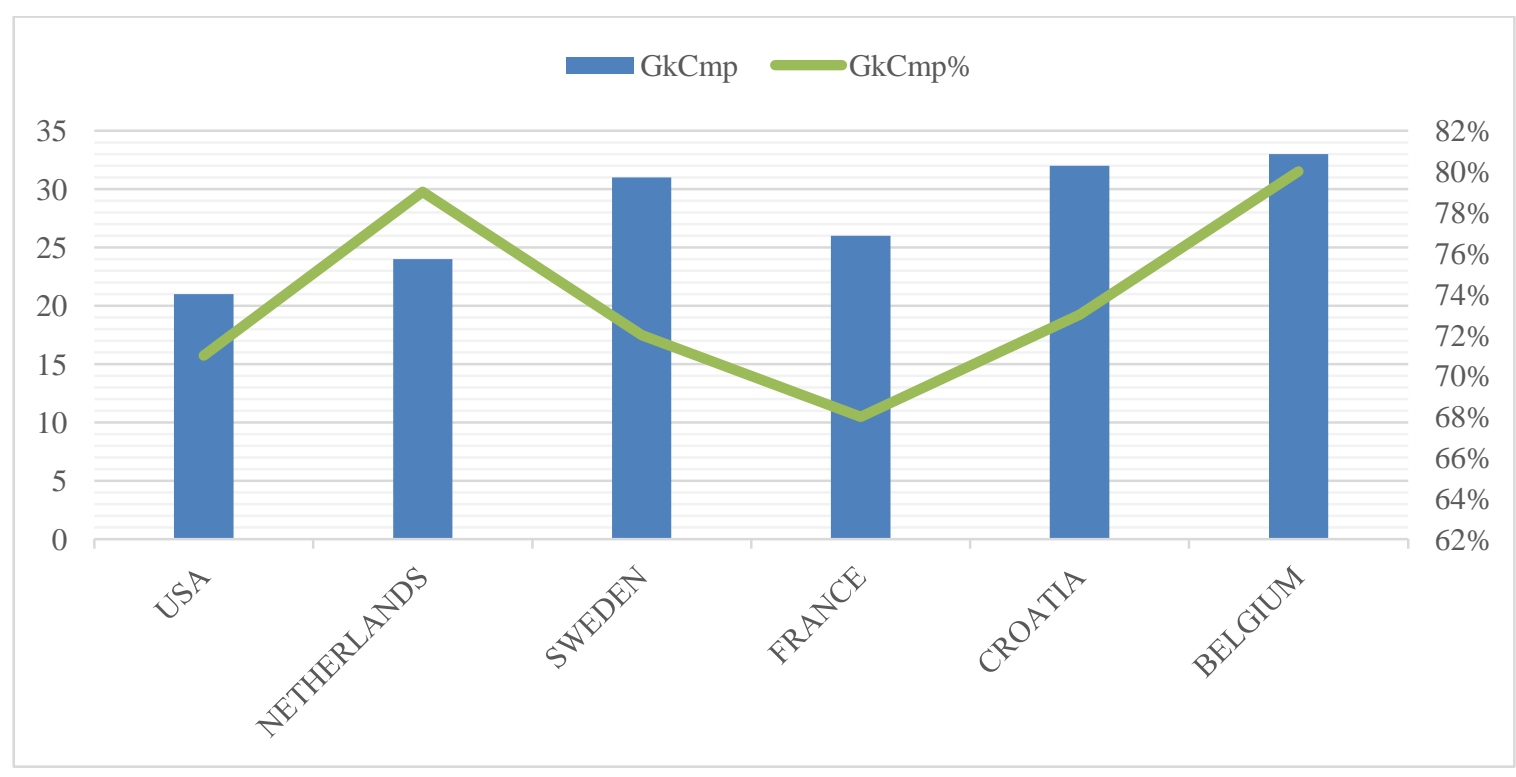

Figure 5. Goalkeeper statistics

For the defensive game, we notice the following results (Table 3):

- An important difference in favour of women in attempted tackles (470 vs. 287); the same trend is maintained in the case of tackles won (294 vs 193). We can thus say that the technique of tackle for women is very correct, which is explained by the small number of cards received;

- Analysing the "pressure" defensive actions, we see it is not very important for a team to perform a large number of such actions but their efficiency (see the case of the US team that has a small number - high success vs. Belgium with a large number - low success); 
- Another difference between men and women in approaching the defensive phase is observed with the help of the "clearances" indicator. Thus, we notice that girls are more concerned with simply solving problematic situations by sending the ball at a distance, while men take more risks of getting the ball out of their own half of the field;

- In the case of the goalkeeper, we notice the growing tendency to pass or actively participate in the construction of the game, the number of passes made by them being important for both genders.

\section{Conclusion}

Between men's and women's high-performance football, there are a number of similarities but also differences in their technical and tactical approaches both offensively and defensively, which is highlighted as follows:

- From an offensive point of view, there is a concern to score as many goals as possible;

- From a defensive point of view, women have a tendency to "positive aggression" (the desire to recover the ball as soon as possible but within the limits of sportsmanship), the number of actions being close to or, in some cases, higher than that of men;

- In both women and men, there is an improvement in the goalkeeper's footwork, a trend revealed by the large number of actions in which they are involved.

We believe that the development directions in women's football follow the path of men's football in technical and tactical terms. However, to increase the level of the show, we consider it appropriate for the field to have smaller dimensions than in men's football.

\section{Authors' Contributions}

All authors have equally contributed to this study.

\section{References}

Althoff, K., Kroiher, J., \& Hennig, E. M. (2010). A soccer game analysis of two World Cups: Playing behavior between elite female and male soccer players. Footwear Science, 2(1), 51-56. https://doi.org/10.1080/19424281003685686

Bradley, P. S., \& Noakes, T. D. (2013). Match running performance fluctuations in elite soccer: Indicative of fatigue, pacing or situational influences? Journal of Sports Sciences, 31(15), 1627-1638. https://doi.org/10.1080/02640414.2013.796062

Casal, C. A., Losada, J. L., Maneiro, R., \& Ardá, A. (2020). Gender differences in technicaltactical behaviour of La Liga Spanish football teams. Journal of Human Sport and Exercise, 16(1), 1-16 (in press). https://doi.org/10.14198/jhse.2021.161.04

Castellano J., Casamichana D., \& Lago-Peñas C. (2012). The use of match statistics that discriminate between successful and unsuccessful soccer teams. Journal of Human Kinetics, 31, 139-147. https://dx.doi.org/10.2478\%2Fv10078-012-0015-7 
D’Ottavio, S. (1998). Didattica del calcio: Insegnamento delle abilità tecniche del giovane calciatore [Football teaching: Training the young footballers' technical skills]. Societa Stampa Sportiva.

FIFA. (2018). World Cup Russia 2018: Technical report. https://img.fifa.com/image/upload/xgwsmrcals5qku0nmrge.pdf

FIFA. (2019). Women's World Cup France 2019: Technical report. https://resources.fifa.com/image/upload/fifa-technical-study-group-fifa-women-s-worldcup-france-2019tm-technical-report.pdf?cloudid=lnpeuvaoc1v5tih9rf7p

Hewitt, A., Norton, K., \& Lyons, K. (2014). Movement profiles of elite women soccer players during international matches and the effect of opposition's team ranking. Journal of Sports Sciences, 32(20), 1874-1880. https://doi.org/10.1080/02640414.2014.898854

Hjelm, J. (2011). The bad female football player: Women's football in Sweden. Soccer \& Society, 12(2), 143-158. https://doi.org/10.1080/14660970.2011.548352

Kirkendall, D., Dawd, W., \& DiCicco, A. (2002). Patterns of successful attacks: A comparison of the Men's and Women's World Cup. Revista de Futbol y Ciencia, 1(1), 2936.

Lewis, D. A., Kamon, E., \& Hodgson, J. L. (1986). Physiological differences between genders: Implications for sports conditioning. Sports Medicine, 3, 357-369. https://doi.org/10.2165/00007256-198603050-00005

Lewis, M. (2019). Some observations: By Women's World Cup technical report. https://www.frontrowsoccer.com/2019/09/22/some-observations-by-womens-world-cuptechnical-report/

Live scores summary. (n.d.). https://www.whoscored.com/

Martinez-Lagunas, V., Niessen, M., \& Hartmann, U. (2014). Women's football: Player characteristics and demands of the game. Journal of Sport and Health Science, 3(4), 258272. https://doi.org/10.1016/j.jshs.2014.10.001

Meier, H., Konjer, M., \& Leinwather, M. (2016). The demand for women's league soccer in Germany. European Sport Management Quarterly, 16(1), 1-19. https://doi.org/10.1080/16184742.2015.1109693

Sainz de Baranda, P., Adán, L., García-Angulo, A., Gómez-López, M., Nikolic, B., \& Ortega-Toro, E. (2019). Differences in the offensive and defensive actions of the goalkeepers at Women's FIFA World Cup 2011. Frontiers in Psychology, 10: 223. https://dx.doi.org/10.3389\%2Ffpsyg.2019.00223

Sarmento, H., Marcelino, R., Anguera, M. T., Campaniço, J., Matos, N., \& Leitão, J. C. (2014). Match analysis in football: A systematic review. Journal of Sports Sciences, 32(20), 1831-1843. https://doi.org/10.1080/02640414.2014.898852

Soroka, A., \& Bergier, J. (2010). Actions with the ball that determine the effectiveness of play in women's football. Journal of Human Kinetics, 26, 97-104. https://doi.org/10.2478/v10078-010-0053-y 